\title{
Iron Deficiency Anemia: A profile of a tertiary care hospital
}

\author{
Rinku Joshi ${ }^{1}$, Dhan Bahadur Shrestha ${ }^{2}$, Drishti RL Shah ${ }^{1}$, Sitaram Khadka ${ }^{3}$
}

${ }^{1}$ Department of Medicine, Shree Birendra Hospital, Chhauni; Nepalese Army Institute of Health Sciences (NAIHS)

${ }^{2}$ Intern, Shree Birendra Hospital, Chhauni; NAIHSm ${ }^{3}$ Department of Medicine, Shree Birendra Hospital, Chhauni

\section{DOI Name}

http://dx.doi.org/10.3126/jaim.v7i1.19575

\section{Keywords}

Iron deficiency anemia, Moderate anemia, nutrition, Nepal.

\section{Citation}

Rinku Joshi, Dhan Bahadur Shrestha, Drishti RL Shah, Sitaram Khadka. Iron Deficiency Anemia: A profile of a tertiary care hospital. Journal of Advances in Internal Medicine 2018;07(01):1-5.

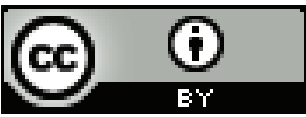

This work is licensed under a Creative Commons Attribution 3.0 Unported License.

\section{ABSTRACT}

Background and aim: Iron deficiency refers to the reduction of iron stores that precedes overt iron deficiency anemia. Iron deficiency anemia (IDA) is the commonest nutritional deficiency around the globe. Though etiology of IDA is multifaceted, and results from the iron demands which is not met by iron absorption in the body, regardless of the reason. This study was aimed to observe the several hematologic parameters among IDA cases presented to a tertiary level referral hospital of Nepal army.

Methods: This prospective hospital based study was conducted among cases of iron deficiency anemia presented to a hematology clinic for six-month duration. With the help of semi-structured questionnaire demographic variables, presenting complaints, baseline laboratory parameters, iron profile and etiology of iron deficiency anemia were recorded. The collected data were entered in SPSS version 22 and analyzed.

Results: In the six-month study period, there were 175 IDA cases who presented to hematology clinic. IDA was more common in females accounting $78 \%$ of 175 cases while rest were male. Mean value of parameters of iron profile were all significantly lower than normal range except TIBC which was significantly raised clinching the diagnosis of IDA. Weakness was the commonest mode of presentation $(83,47.4 \%)$. Poor intake was the main culprit of IDA $(88,50.3 \%)$. Most of the cases $(82,46.9 \%)$ belonged to moderate anemia group. Severity of anemia was associated with platelet count and total leucocyte count $(p<0.05)$ while it was not associated with iron profile values ( $p>0.05)$.

Conclusion: In adult group, IDA is more common in women and non-specific symptoms like weakness is the commonest mode of presentation. Poor dietary intake is the main cause of IDA in our context. Among IDA cases, most of them belonged to moderate anemia.

\section{INTRODUCTION}

Iron deficiency refers to the reduction of iron stores that precedes overt iron deficiency anemia. ${ }^{1}$ Iron deficiency anemia (IDA) is the commonest nutritional deficiency around the globe with considerable impact on health affecting 2 percent in adult men, 9 to 12 percent in non-Hispanic white women, and nearly 20 percent in black and Mexican-American women. ${ }^{1-4}$ Though etiology of IDA is multifaceted, and results from the iron demands which is not met by iron absorption in the

\footnotetext{
* Corresponding author

Dr. Dhan Bahadur Shrestha

Birendra Hospital, Chhauni, Kathmandu

e-mail:medhan75@gmail.com
} 
body, regardless of the reason. Notable causes are inadequate intake, impaired absorption or transport, physiologic losses associated with chronological or reproductive age, or chronic blood loss secondary to disease. ${ }^{3,5,6}$ It has a great public health significance affecting children, adolescents and women of reproductive age worldwide. ${ }^{7,8}$ Worldwide, prevalence of IDA is estimated to be $20-80 \%$ among reproductive age female population and has impact on the both fetal and maternal health. ${ }^{9}$ Iron supplement in antenatal period has pivotal role. ${ }^{10}$ Anemia reduces physical work capacity and cognitive function and adversely affects learning and school performance in schoolgirls entering adolescence so it needs the proper address on time. ${ }^{11}$

One study from Nepal showed, the prevalence of anemia, $12 \%$; depleted iron stores, $20 \%$; IDA, $6 \%$ and iron deficient erythropoiesis in $7 \%$ of non-pregnant women of reproductive age group respectively. ${ }^{12}$

This study was aimed to observe several hematologic parameters among IDA cases presented to the tertiary level referral hospital of Nepal army as such study have not been conducted so far.

\section{METHODS}

\section{Selection and Description of Participants}

This single centered, prospective cross-sectional study was conducted among anemic patients presented to hematology clinic and kept under regular follow up of a tertiary level hospital in Kathmandu over a period of six months from June to December 2017. With the help of semi-structured questionnaire demographic variables, presenting complaints, baseline laboratory parameters, iron profile and etiology of iron deficiency anemia were recorded. All the diagnosed cases of IDA were evaluated for the etiology and treated with iron therapy based on severity and standard protocol and kept under regular follow-up. Again, iron profile was repeated among all cases at third month of follow up.

The study proposal was approved by ethical review committee (IRC) of Nepalese army institute of health sciences (NAIHS). Informed verbal consent was taken while enrolling the individual in the study.

\section{Statistics}

The collected data were entered in SPSS version 22 and analyzed. Chi-square test was used to see association between severity of iron deficiency anemia with other variables with the help of $p$ value based on $95 \%$ confidence interval and $5 \%$ standard error

\section{RESULT}

In the six-month study period, there were 175 iron deficiency anemia cases who presented to hematology clinic. Proper evaluation was done with physical examination and laboratory parameters to see overall health status and severity of anemia. The mean age of patients was $52.61 \pm 15.44$ years and hemoglobin $8.46 \pm 1.5 \mathrm{gm} / \mathrm{dl}$. Mean value of parameters of iron profile were all significantly lower than normal range except TIBC which was significantly raised clinching the diagnosis of IDA (Table 1.).

\begin{tabular}{lrrrr}
\hline & Min. & Max. & \multicolumn{1}{c}{ Mean } & $\begin{array}{c}\text { Std. Devia- } \\
\text { tion }\end{array}$ \\
\hline AGE & 15 & 87 & 52.61 & 15.441 \\
Hemoglobin & 2.0 & 10.9 & 8.465 & 1.5479 \\
TC & 2400 & 15200 & 6317.66 & 2367.921 \\
Platelets & 50000 & 534000 & 255091.43 & 104322.680 \\
MCV & 49.0 & 77.0 & 68.459 & 5.4183 \\
MCH & 13.0 & 32.0 & 23.614 & 3.8159 \\
MCHC & 18.8 & 34.9 & 29.581 & 2.6316 \\
RDW & 14.5 & 23.0 & 16.919 & 1.3517 \\
Serum Iron & 1.9 & 49.0 & 20.526 & 12.3642 \\
Serum Ferritin & 1.0 & 80.0 & 15.336 & 11.5330 \\
TIBC & 192.0 & 589.0 & 341.674 & 82.8368 \\
Ferritin at 3 months & 18.0 & 236.0 & 82.023 & 36.7930 \\
\hline
\end{tabular}

Table 1. Descriptive parameters of IDA cases

IDA was more common in females accounting $78 \%$ of 175 cases and rest were male (Figure 1.)

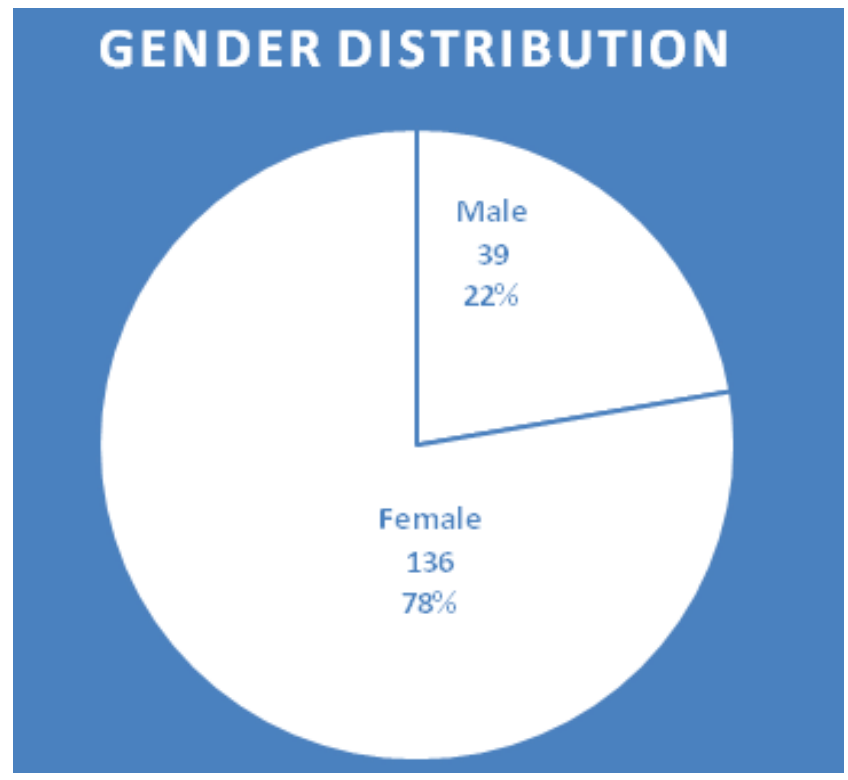

Figure 1. Gender distribution of IDA

Among the cases of IDA, commonest mode of presentation 
was generalized weakness $(83,47.4 \%)$. Other symptoms were per-vaginal (PV) bleeding, upper gastrointestinal (UGI) bleeding, per-rectal (PR) bleeding, Shortness of breath (SOB), bleeding due to road traffic accident, paleness etc. (Table 2.).

\begin{tabular}{lcc}
\hline \multicolumn{1}{c}{ Presenting complaint } & Frequency & Percent \\
\hline Weakness & 83 & 47.4 \\
PV Bleeding & 35 & 20.0 \\
UGI bleeding & 30 & 17.1 \\
SOB & 7 & 4.0 \\
PR Bleeding & 7 & 4.0 \\
Other cause of Blood Loss & 6 & 3.4 \\
Paleness & 4 & 2.3 \\
Myalgia & 3 & 1.7 \\
Total & 175 & 100.0 \\
\hline
\end{tabular}

Table 2. Mode of presentation of IDA cases

Among the cases of IDA, most common cause was nutritional, due to poor intake $(88,50.3 \%)$, followed by UGI bleeding and other mode of blood loss (Table 3.).

\begin{tabular}{lrr}
\hline \multicolumn{1}{c}{ Cause of IDA } & Frequency & Percent \\
\hline Nutritional & 88 & 50.3 \\
UGI bleeding & 38 & 21.7 \\
Menorrhagia & 18 & 10.3 \\
Fibroid & 10 & 5.7 \\
LGI Bleeding & 8 & 4.6 \\
Ca CX & 7 & 4.0 \\
Other cause of Blood loss & 5 & 2.9 \\
PTB & 1 & .6 \\
Total & 175 & 100.0 \\
\hline
\end{tabular}

Table 3. Etiology of IDA

Based on level of hemoglobin IDA cases were categorized into mild, moderate, severe and life-threatening anemia. Most of the cases $(82,46.9 \%)$ were belonging to moderate anemia group (Table 4.)

\begin{tabular}{lrr}
\hline Severity of anemia & Frequency & Percent \\
\hline Moderate Anemia (8-10) & 82 & 46.9 \\
Severe Anemia (6.5-8) & 47 & 26.9 \\
Mild Anemia (above 10) & 30 & 17.1 \\
Life threatening (less than 6.5) & 16 & 9.1 \\
Total & 175 & 100.0 \\
\hline
\end{tabular}

Table 4. Severity of IDA

In all patients, MCV was lower than normal while RDA was high. In most of the cases (132), peripheral blood film showed microcytic hypochromic anemia while in rest (43) there was associated polychromasia and anisopoikilocytosis. In most ( $>75 \%$ ) of the cases studied; $\mathrm{MCH}, \mathrm{MCHC}$, serum ferritin was lower than normal. Only in 2 cases, serum ferritin was not corrected after 3 months of the treatment while in rest, it was normalized. Severity of anemia was associated with platelet count and total leucocyte count $(p<0.05)$ while severity was not associated with iron profile study ( $p>0.05$ ) (Table 5.).

\begin{tabular}{|c|c|c|c|c|c|c|c|}
\hline & Variables & $\begin{array}{l}\text { Mild } \\
\text { Anemia } \\
\text { (above } \\
\text { 10) }\end{array}$ & $\begin{array}{l}\text { Moderate } \\
\text { Anemia } \\
(8-10)\end{array}$ & $\begin{array}{l}\text { Severe } \\
\text { Anemia } \\
(6.5-8)\end{array}$ & $\begin{array}{l}\text { Life threat- } \\
\text { ening (less } \\
\text { than 6.5) }\end{array}$ & Total & $p$-value \\
\hline \multirow[t]{3}{*}{ Total counts } & Less than 4000 & 1 & 7 & 5 & 0 & 13 & .011 \\
\hline & Normal (4-11000) & 29 & 70 & 41 & 12 & 152 & \\
\hline & Higher than 11000 & 0 & 5 & 1 & 4 & 10 & \\
\hline \multirow[t]{3}{*}{ Platelets } & Less than 150000 & 5 & 13 & 10 & 3 & 31 & .026 \\
\hline & Normal (150-450000) & 24 & 69 & 34 & 10 & 137 & \\
\hline & Higher than 450000 & 1 & 0 & 3 & 3 & 7 & \\
\hline \multirow{3}{*}{$\begin{array}{l}\text { Peripheral } \\
\text { Blood Films }\end{array}$} & MHA & 22 & 61 & 37 & 12 & 132 & .255 \\
\hline & $\begin{array}{l}\text { MHA with Polychroma- } \\
\text { sia and anisopoikilo- } \\
\text { cytosis }\end{array}$ & 2 & 11 & 7 & 4 & 24 & \\
\hline & $\begin{array}{l}\text { MHA with Anisopoikilo- } \\
\text { cytosis }\end{array}$ & 6 & 10 & 3 & 0 & 19 & \\
\hline MCV & Less than 78 & 30 & 82 & 47 & 16 & 175 & - \\
\hline \multirow[t]{2}{*}{ MCH } & Less than 27 & 20 & 63 & 38 & 13 & 134 & .509 \\
\hline & Normal (27-33) & 10 & 19 & 9 & 3 & 41 & \\
\hline \multirow[t]{2}{*}{ MCHC } & Less than 33 & 29 & 72 & 45 & 15 & 161 & .283 \\
\hline & Normal (33-35) & 1 & 10 & 2 & 1 & 14 & \\
\hline RDW & High (More than 14) & 30 & 82 & 47 & 16 & 175 & - \\
\hline \multirow{2}{*}{$\begin{array}{l}\text { Serum Fer- } \\
\text { ritin }\end{array}$} & Less than 20 & 23 & 64 & 41 & 11 & 139 & .376 \\
\hline & Normal (20-400) & 7 & 18 & 6 & 5 & 36 & \\
\hline \multirow{2}{*}{$\begin{array}{l}\text { Serum } \\
\text { ferritin at } 3 \\
\text { months }\end{array}$} & Less than 20 & 0 & 1 & 1 & 0 & 2 & .816 \\
\hline & Normal (20-400) & 30 & 81 & 46 & 16 & 173 & \\
\hline \multirow[t]{3}{*}{ TIBC } & Less than 250 & 3 & 11 & 8 & 1 & 23 & .713 \\
\hline & Normal (250-370) & 13 & 41 & 25 & 10 & 89 & \\
\hline & High (More than 370) & 14 & 30 & 14 & 5 & 63 & \\
\hline
\end{tabular}

Table 5. Severity of anemia and its relation with other parameters

\section{DISCUSSION}

Iron deficiency anemia is a common hematological problem in medical practice with more burden in developing and underdeveloped world. ${ }^{1,13}$ In this study, the mean age of patients was $52.61 \pm 15.44$ years and hemoglobin $8.46 \pm 1.5 \mathrm{gm} / \mathrm{dl}$. Similarly, other studies also support high prevalence of anemia in extreme of age due to several factors. ${ }^{14,15}$ One study concluded high prevalence of anemia after 50 years, and older counting 
greater than $20 \%$ by 85 years. In older age group there is tendency of having anemia either due to nutritional or chronic diseases. ${ }^{15}$

IDA presents with nonspecific symptoms due to poor oxygen carrying capacity of blood. IDA can be result of various factors like dietary factor, blood loss and parasitic infestations. ${ }^{1,6}$ In this study, commonest mode of presentation was generalized weakness and blood loss from gastrointestinal tract. Among the cases of IDA, most common cause was nutritional, due to poor intake $(50.3 \%)$, followed by UGI bleeding. Most of the cases (46.9\%) belonged to moderate anemia group in present study while some study has reported mild anemia as the commonest entity in elderly group. ${ }^{15}$ Iron profile study is the commonly performed laboratory study to diagnose IDA. In most cases, MCV, serum ferritin will be low while iron binding capacity will be high. And there will be typical picture of IDA in peripheral blood film. ${ }^{1,6}$

Peripheral blood film showed microcytic hypochromic anemia in 132 cases while in rest there was associated polychromasia and anisopoikilocytosis in current study. Severity of anemia were associated with platelet count and total leucocyte count $(p<0.05)$ while severity was not associated with iron study ( $p>0.05)$ in this study while such things has not been mentioned in previous studies.

\section{CONCLUSION}

In adult group, women are most commonly affected and nonspecific symptoms like generalized weakness is the commonest mode of presentation of IDA. Poor dietary intake is the main cause of IDA in our context. Among IDA cases, most of them belonged to moderate anemia group. Severity of anemia was associated with total leucocyte count and platelets while iron profile and severity of anemia did not show any association. This small study was conducted among army personnel and their family in a tertiary level hospital but to make it generalizable, further study may be needed with a large sample size.

\section{REFERENCES}

1. Camaschella C. Iron-deficiency anemia. New England Journal of Medicine. 2015 May 7;372(19):183243. DOI: https://doi.org/10.1056/NEJMra1401038 PMid:25946282

2. Killip S, Bennett JM, Chambers MD. Iron deficiency anemia. American family physician. 2007;75.

3. Clark SF. Iron deficiency anemia. Nutrition in clinical practice. 2008 Apr;23(2):128-41. https://doi. org/10.1177/0884533608314536 PMid:18390780

4. Johnson-Wimbley TD, Graham DY. Diagnosis and management of iron deficiency anemia in the 21st century. Therapeutic advances in Gastroenterology. $2011 \quad$ May;4(3):177-84. https://doi. org/10.1177/1756283X11398736 PMid:21694802 PMCid:PMC3105608

5. Pasricha SR, Flecknoe-Brown SC, Allen KJ, Gibson PR, McMahon LP, Olynyk JK, Roger SD, Savoia HF, Tampi R, Thomson AR, Wood EM. Diagnosis and management of iron deficiency anaemia: a clinical update. Med J Aust. 2010 Nov 1;193(9):525-32. PMid:21034387

6. Miller JL. Iron deficiency anemia: a common and curable disease. Cold Spring Harbor perspectives in medicine. $2013 \mathrm{Jul} \mathrm{1;3(7):a011866.} \mathrm{https://doi.}$ org/10.1101/cshperspect.a011866 PMid:23613366

\section{PMCid:PMC3685880}

7. Umeta M, Haidar J, Demissie T, Akalu G, Ayana G. Iron deficiency anaemia among women of reproductive age in nine administrative regions of Ethiopia. The Ethiopian Journal of Health Development (EJHD). 2016 Nov 8;22(3).

8. Panigrahi A, Sahoo PB. Nutritional anemia and its epidemiological correlates among women of reproductive age in an urban slum of Bhubaneswar, Orissa. Indian journal of Public health. 2011 Oct 1;55(4):317. https://doi.org/10.4103/0019557X.92415 PMid:22298143

9. Breymann C. Iron deficiency anemia in pregnancy. InSeminars in hematology 2015 Oct 31 (Vol. 52, No. 4, pp. 339-347). WB Saunders. http://dx.doi. org/10.1053/j.seminhematol.2015.07. 003

10. Pasricha SR, Low M, Thompson J, Farrell A, DeRegil LM. Iron supplementation benefits physical performance in women of reproductive age: a systematic review and meta-analysis. The Journal of nutrition. 2014 Jun 1;144(6):906-14. https://doi. org/10.3945/jn.113.189589 PMid:24717371

11. Akramipour R, Rezaei M, Rahimi Z. Prevalence of iron deficiency anemia among adolescent schoolgirls from Kermanshah, Western Iran. 
Hematology. 2008 Dec 1;13(6):352-5. https://doi. org/10.1179/102453308X343383 PMid:19055864

12. Chandyo RK, Strand TA, Ulvik RJ, Adhikari RK, Ulak M, Dixit $\mathrm{H}$, Sommerfelt $\mathrm{H}$. Prevalence of iron deficiency and anemia among healthy women of reproductive age in Bhaktapur, Nepal. European journal of clinical nutrition. 2007 Feb 1;61(2):262-9. https://doi. org/10.1038/sj.ejen.1602508 PMid:16929243

13. Kassebaum NJ, Jasrasaria $R$, Naghavi $M$, et al. A systematic analysis of global anemia burden from 1990 to 2010. Blood 2014;123:615-624. https://doi. org/10.1182/blood-2013-06-508325 PMid:24297872 PMCid:PMC3907750
14. Guyatt GH, Patterson C, Ali M, Levine M, Turpie I, Meyer R, Singer J. Diagnosis of iron-deficiency anemia in the elderly. The American journal of medicine. 1990 Mar 1;88(3):205-9. https://doi.org/10.1016/00029343(90)90143-2

15. Guralnik JM, Eisenstaedt RS, Ferrucci L, Klein HG, Woodman RC. Prevalence of anemia in persons 65 years and older in the United States: evidence for a high rate of unexplained anemia. Blood. 2004 Oct 15;104(8):2263-8. https://doi.org/10.1182/ blood-2004-05-1812 PMid:15238427 